\title{
Theories of meaning and different perspectives on information systems
}

\author{
P. Holm and K. Karlgren \\ Department of Computer and Systems Science, Stockholm University, \\ Electrum 230, 16440 Kista, Sweden \\ Telephone: + 468162000 , Telefax: +4687039025 \\ E-mail: \{pholm,klas\}@dsv.su.se,
}

\begin{abstract}
Even though automated information systems have been used in work life for almost three decades, the academic discipline of information systems development is still in a "preparadigmatic phase'. There is no central corpus of a well understood and accepted theory of how these artifacts should be understood and designed. What we see is a set of scattered methods and theories, with influences from a wide variety of other disciplines, such as logic, linguistics, philosophy, cognitive psychology, organizational theory, ethnography, etc. There is a practical need for creating an overview and a deeper understanding of how different theories and methods are related to each other, what their relative strengths and weaknesses are and when they are applicable.

In this paper we will present such an overview, based on a discussion about different theories of meaning. A framework is presented that divides the usage context of an information system into three areas of interest: referential aspects, individual aspects, and social aspects. Different theories elaborate on these aspects in different ways and to different degrees. There are strong analogies between these theories and philosophical theories of meaning that elaborate on corresponding aspects. To bring out these analogies we discuss the strengths and weaknesses of a set of approaches: (1) the traditional mainstream focus on referential aspects, (2) the adoption of cognitive theories in the information systems field, (3) structured theories about the social and communicative usage of information systems, e.g., theories based on the speech act theory, and (4) 'usage holism' and the criticisms of the role of abstract, theoretical modeling and analysis during information systems development. The paper does not present a final solution to the problems we address. Rather, it should be read as a contribution to what we believe must be an ongoing debate and a long term reflection on the theoretical foundation of information systems-research.
\end{abstract}

\section{Keywords}

Theories of meaning, information systems design, information systems development 


\section{Words of wisdom}

The vision and blindness of a philosopher go together. He has vision, yet usually at the same time is blinded by his vision. Hence the excellence of his philosophy is at the same time its shortcoming. (Hsün Tzu, $298-238$ B.C.)

\section{INTRODUCTION}

In this paper we will give an account of some of the most widespread theories of meaning: the referential, ideational, 'traditional', stimulus-response, and the use-theory. We will present a discussion framework that is based on a division of the language usage context into three areas of interest. It is an illustration of aspects considered more or less by different theories of meaning. We will then use the same framework for discussing different perspectives on (automated) information systems. We will discuss some 'clear cases', where there are evident similarities between a method in the discipline of information systems development and analogous theories in the area of philosophy of language, e.g. the application of cognitivistic theories in artificial intelligence and human-computer interaction, the Sampo method (Auramäki et al, 1988), the Co-ordinator and its followers in the area of computer supported cooperative work (Medina-Mora et al, 1993; Winograd, 1987), the Tools approach (Ehn, 1988), and the Human-activity approach (Bødker, 1991).

An article that addresses similar issues as this one has been written by Lyytinen (Lyytinen, 1985). While he presents five particular language views (Fregean core, generative grammar, Piaget's cognitive view, behaviorism, and use theories), and their adoption into the area of information systems (IS) research and development, we try to give an overview of the underlying differences between these and other theories, in terms of our three areas of interest. We will use our framework to illustrate the difference between the language game approach and the speech act theory as developed by Austin and Searle. Lyytinen, on the other hand, treats all use theories under one label. Moreover, we call attention to how ideas and terminology borrowed from the field of philosophy of language are used differently in the IS-field. Finally we believe that our framework can be used as a basis to create a structured overview of different kinds of requirements that need to be addressed in a concrete development situation. In this respect it can be compared to the 'four worlds approach' (Jarke, 1991; Jarke and Pohl, 1993).

Another and complementary approach is taken in (Bickerton and Siddiqi, 1992; Hirschheim and Klein, 1989), who give an overview of different methods and theories in the IS-field based on their underlying assumptions about work and work organizations.

\section{THEORIES OF MEANING}

\subsection{The referential theory}

According to the referential theory, the meaning of an expression is what it refers to, or stands for (Lyons, 1981). E.g., 'John' means John. The referential theory typically focuses on a proper name and what is named (Alston, 1967). At first, nothing seems to be problematic: on the one hand there is the name 'John' and on the other the man who is named. One variant of the theory identifies meaning with what it refers to and another identifies meaning with the relation between the name and what is referred to.

A problem with the first variant, pointed out by Frege, is that two expressions can refer to the same entity yet not have the same meaning (ibid.). One does not just by understanding the 
meaning of the expressions understand that they refer to the same entity so meaning cannot be identical with the object of reference. A difficulty with the other variant is the assumption that every word does refer to something. There are classes of words, such as prepositions and conjunctions, which do not seem to refer to any objects.

\subsection{The 'traditional' theory}

The main idea in the 'traditional' theory of meaning, with its roots in Greek philosophy, is the distinction between the meaning (intension, connotation, Sinn, sense) of an expression and its referent (extension, denotation, Bedeutung) (Føllesdal et al, 1990). Charles Kay Ogden illustrated the relationships between expression, meaning and referent in a triangle.

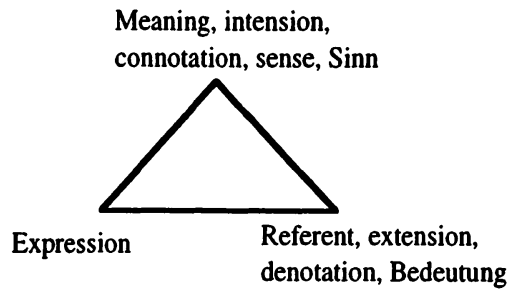

Figure 1 Ogden's Triangle (including alternative terms).

Meaning is what the expression expresses. It is what is grasped when a person understands the expression. When a person who knows the language hears or sees an expression he grasps the meaning expressed.

The meaning of an expression is distinguished from its referent which is the thing we speak about when we use the expression, what the expression refers to. The meaning is something abstract and can only be grasped by our intellect while the referent can be something quite concrete such as a dog, a person or a tree. A possible question is: But, what is this thing called 'sense' or 'meaning'? One possible answer is given by the ideational theory.

\subsection{The ideational theory}

According to an ideational theory, words are marks of the ideas within the speaker's mind and communication is achieved when the words excite the same ideas in the hearer as they stand for in the speaker. The meaning of an expression is the idea or concept, associated with it in the mind of anyone who knows it (Lyons, 1981). Even if one at times speaks without being conscious of the associated ideas one does not understand the word unless one could call it up (Alston, 1967). But it does not seem to be the case that there is an idea in one's mind corresponding to every linguistic unit one hears or speaks. Consider the words in the previous sentence: But - it - does - ... It does not seem possible to produce a distinctive idea for each word.

There are difficulties even for words for which it is easy to produce an image. A problem is that there is no one-to-one correspondence between the image and the word. For instance, the image of the word 'dog' could be a sleeping dog, a running dog, a beagle or a hound. And the image of a dog can correspond to numerous words, e.g., 'dog', 'warning', 'pet', or 'animal'.

Another problem with the ideational theory is that we do not settle questions about meaning by looking for ideas. The fact that there is public consensus on what words mean suggests that meaning is a function of publicly observable aspects of the use of language. This has led some theorists to base a theory of meaning on factors present in the situation where speech occurs. 


\subsection{The stimulus-response theory}

The stimulus-response theory defines the meaning of an expression as the situation in which the speaker utters it and the response or disposition to respond which it calls forth in the hearer (ibid.). A problem is that any word can occur in a wide variety of situations that have nothing in common which is distinctive of the word. Furthermore different responses may follow a given word depending on the situation, and sometimes there follows no overt response at all.

The theory is burdened with the assumption that every word is a sign for a thing, aspect, or state of affairs (Alston, 1967). Another problem is associating the right response with the right word - it is assumed that there is a certain response which occurs every time a word is spoken. It seems there could be an infinite number of dispositions produced by an utterance.

Each of the theories mentioned so far is based on an insight into the nature of meaning: (1) language is used to refer to objects, (2) language is used to express our ideas, and (3) words have meaning in a physical context of human activity. But it is an oversimplification to say that meaning is identified with only one of these aspects. Most theories of meaning are also based on the notion that a word must be followed by one certain aspect or thing on every occasion of its use, and the theories are therefore formulated as answers to the question "what sort of entity is meaning?'.

\subsection{Meaning is use}

A different way of looking at language and meaning was established by Ludwig Wittgenstein. His work is in a way a criticism of all the theories of meaning mentioned above. One of the main points in the major work of the later Wittgenstein, 'Philosophical Investigations', is a negative one. It states what meaning is not. His view emphasizes the use of words and language: it is the way an expression is used that gives it its meaning. The meaning of an expression is identified with its use, but meaning can not be identified with any particular aspects of the usage environment, neither the referent nor a mental idea. According to Wittgenstein, it is a mistake to try to locate the meaning of a word in some realm or other, to look for a certain sort of entity that constitutes meaning. Instead meaning depends on the whole context of use, the whole language game, the whole 'form of life' that the participants share. Wittgenstein's primary contribution is thus to introduce a holistic perspective on meaning. We have labeled this 'usage holism'. It is not to be confused with 'semantic holism', which could be described as asserting: 'In order to understand an expression, you need to understand a whole language.'. Usage holism, on the other hand, could be described as follows: 'In order to understand an expression, you need to master a set of practical activities in which this expression is used.'.

When Wittgenstein argues for this holistic view, he exemplifies how aspects of the usage context, other than the ideational and referential aspects, affect the meaning of an expression, e.g., social relations between different language users. A second contribution of Wittgenstein is hence that he has inspired others to focus on new aspects of the usage environment, in addition to (or opposed to) the referential and ideational aspects. Both speech act theory and behaviorism have been influenced by Wittgenstein in this respect.

Wittgenstein emphasized that language has many different functions - not only to convey ideas or refer to objects - and he also stressed that speaking is doing something. Besides informing, speaking may be doing a number of things such as asking, joking, begging, requesting, convincing, etc. Speech act theory has tried to describe how people use language in terms of speech acts. There is a clear appeal to aspects that lays outside the realm of the referent or the mental ideas of the language user. The factors that make an utterance a command or a 
description can be, e.g., the bodily behavior of a speaker, the eye movements, pitch, the location of the utterance, the social role of the speaker, etc.

Speech act theory is often labeled as a 'meaning is use theory' together with the philosophy of the later Wittgenstein. Both associate the meaning of an expression with how it is used. However, it is also important to see the differences between the two. Searle associated meaning with a limited set of rules for how an expression should be used to perform certain actions. With this as a basis, he created a taxonomy of different types of speech acts. For Wittgenstein, on the other hand, meaning is related to the whole context of use and not only a limited set of rules. It can never be fully described in a theory or by means of systematic philosophy.

\section{A FRAMEWORK FOR DISCUSSING DIFFERENT THEORIES OF MEANING}

Our framework for discussing different theories of meaning is illustrated in figure 2 . It is an overview of aspects considered by many theories of meaning.

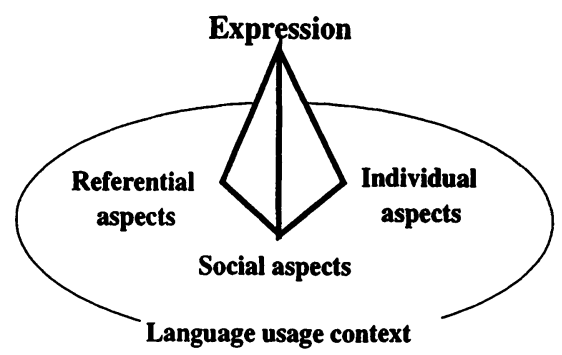

Figure 2 A framework for discussing different theories of meaning.

The referential aspects constitute the first part of our framework, i.e., what the language expressions are about, what they denote or refer to. As noted above, there are good reasons for including more than just the referential aspects in a theory of meaning. Despite this, there is still today a heavy focus on the referential aspects. One might argue that a large part of understanding the mechanism by which language acquires its meaning is to understand its complex mechanisms of reference.

The individual aspects constitute the second part of our framework. Several theories of meaning are based on the insight that we need to consider also the language user to give an account of meaning. This is typically done by the ideational theory.

The social aspects constitute the third part of our framework. Several theories of meaning are based on the insight that we need to consider several language users to give an account of meaning. Different philosophers appeal to the social aspects for different purposes. Some have tried to understand the mechanisms that make people agree to use certain words for certain purposes, e.g., that certain words shall refer to certain things. What is it that makes 'chair' refer to chairs? Some examples of this are the causal theory of proper names, Lewis' theory about signaling and conventions (Martin, 1993), and Putnam's idea of division of linguistic labor (Pagin, 1994).

However, the kind of interest in the social aspects that we would like to emphasize is the contribution made by the use theories, which has to do with understanding the functional role of language in social interaction. Typical examples of philosophers with this focus are Wittgenstein, Austin, Searle, Grice, and Habermas. This kind of language-usage analysis can 
be done for descriptive utterances. However, it has a special relevance for non-descriptive utterances. How can you describe the meaning of a promise unless you describe its functional role in the interaction between people?

Some of the most debated issues in contemporary philosophy of language concern how to view the individual language user. How can we, e.g., refer to a person's inner thoughts and ideas? What status do introspective reports have? Should we, perhaps, restrict theories of language to refer only to publicly available facts, like the external behavior of the language users? Wittgenstein's private language argument is held by many to be conclusive on this matter. It concludes that meaning can not be explained by reference to private items, since meaning has to do with social criterias for right and wrong language behavior. The argument opposes the idea that we can think of a competent language user as a person with internal rules in a private 'language of thought'

\subsection{The scope of this framework}

We want to end this section, by saying something about what is not covered in the framework presented above. We have, for instance, no platonic heaven of ideas. You may also need to add a discussion about how you can view the internal structure of the language in different ways, e.g., whether you believe it has a compositional structure, or if you adopt a holistic perspective. Finally, it could be meaningful to extend the notion of 'referential aspects' to be 'the physical context of the language usage situation', of which the referential aspects are only one part. E.g., according to the stimulus-response theory, the potential stimuli that may affect the language subject may be something more than just the referent of an expression.

\section{A FRAMEWORK FOR DISCUSSING DIFFERENT PERSPECTIVES ON INFORMATION SYSTEMS}

We will use an analogous framework to discuss different methods and theories in the discipline of information systems development. It is illustrated in figure 3 and divides the information system's usage context into three areas of interest.

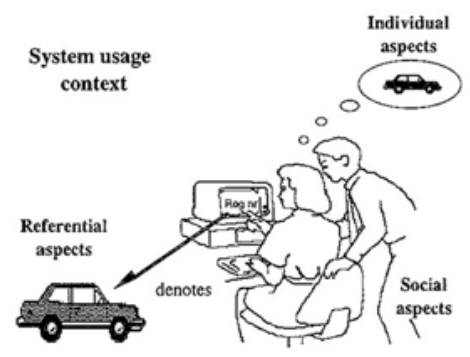

Figure 3 A framework for discussing different perspectives on information systems.

We will use this framework to draw conclusions regarding the strengths and weaknesses of different approaches, by pointing out analogies to theories of meaning. It can be summarized as follows: 1) In analogy to the situation within the philosophy of language, there is a mainstream focus on referential aspects. This focus tends to neglect the usage situation, both its individual 
and social aspects. 2) The field of computer science is influenced by theories from cognitive science in various ways. There is a risk that we use theories with an individualistic focus to address social issues. 3) There is a trend today to focus more on the social and organizational aspects. It is stressed that language has many different functions. Ideas and terminology are borrowed from corresponding theories within the philosophy of language, e.g., from the speech act theory as developed by Searle. 4) The anti-theoretical tendency of the language game perspective corresponds to the discussion about the role of abstract, theoretical modeling and analysis during information systems development, which in turn is related to the purpose of organizational change - to increase effectiveness and control or to strive for flexibility and empowerment.

\subsection{Conceptual modeling and database technology}

Analogous to the situation in the area of philosophy of language, there is a major corpus of work in the field of information systems research that focuses on the referential aspect. This focus is especially strong and explicit in the area of conceptual modeling and database technology, where a classical model theoretical way of thinking is dominating. There is a general objective of finding graphical modeling techniques that are easy to understand for noncomputer-experts, which at the same time have a formal and precise interpretation. It is common to view the conceptual model as an early version of a database schema. It is viewed as a logical theory that describes part of the same universe of discourse (the same domain) as the database. The conceptual model is created to reach an agreed 'correct' understanding of the domain.

The major advantages with this approach have to do with ensuring the reliability of a future information system. It can be criticized for presupposing that all information is used for one purpose only, i.e., to describe things. This is what Austin labeled 'the descriptive fallacy'. But, what about customer contracts, promises, and customer orders? How can you understand the meaning of the information in a customer contract, without taking into account how the contract is used in practical life (the usage aspects)? This is a discussion about social relations and commitments. In traditional conceptual modeling, as described above, the usage situation is not represented in the models at all. This means that there is little theoretical support in describing why certain types of information are needed.

The basic distinction between referential and usage (= individual and social) aspects, can also be used to clarify the relevance and purpose of enterprise modeling in the context of systems design and development. Conceptual modeling has moved more and more into this area. An enterprise model could be relevant for revealing something about the usage environment of the system, i.e., the work activities that should be supported by the system. From this we may derive specific information needs. We may also use it to analyze the utility and value of the system, and to describe the functional role of both information and information technology. However, when we have modeled an organization, we have often also gained knowledge about the domain of the system, since many automated office information systems are about the organization. There is often a tendency to think that what we see in our conceptual models, e.g., an enterprise model, is primarily a potential software specification, when in fact it has a double purpose, i.e. to describe both usage and referential aspects. Maybe this tendency can be interpreted as a historical inheritance from the early childhood of computers and office automation. In those days, computerization often resulted in the automation of existing manual work routines. To analyze the existing routines was an important means to analyze what the system should do. Computerization today typically results in a different type of change in the organization. Hence enterprise modeling as a means to analyze and understand the usage environment of the system has become more important. 


\subsection{Speech act based methods and computer supported cooperative work}

The methods and theories in the area of computer supported cooperative work are naturally associated with a focus on social aspects. The basic concern is to understand why people need to communicate at work for different purposes. Important concepts are cooperation, coordination, and articulation of work (Schmidt, 1993). Information technology is seen as a media for enhancing social communication. In this context versions of the Searlian speech act theory (Searle, 1969, 1979; Searle and Vanderveken, 1985) have been applied, based on the well-known schema for 'conversation for action' developed by Winograd, Flores et al (Flores et al, 1988; Winograd, 1988; Medina-Mora et al, 1992). In recent years there has been a kind of breakthrough in industry with respect to methods related to this approach in the so called workflow management area (Schäl and Zeller, 1993). Also the development of the Sampo method can be considered as pioneering work in applying a speech act theoretical approach in the area of information systems development (Auramäki et al, 1988; Auramäki et al, 1992).

The relation between these methods and traditional conceptual modeling, as described above, is analogous to the relation between the use theory and a focus on the referential aspects in the field of philosophy of language. It introduces a perspective where the functional role and the purpose of communication in the work setting are explored. In more traditional approaches the usage of information is described simply in terms of input and output, or in data-flow diagrams. Lyytinen has labeled this perspective 'the data storage paradigm'. Information is viewed in analogy with things that are moved around.

The criticism of the usage of speech act theory in the IS-field is also partly analogous to the corresponding criticism in the area of philosophy of language. The strong appeal to a limited set of conventions and rules has been criticized since it tends to overlook the contingencies of work and communication (Schmidt, 1993; Suchman, 1993). This critique is related to the usage holism, described below. Another line of criticism concerns the theory of communicative actions by Habermas. He classifies communicative actions using the basic intentions: claim to justice, claim to truth, and claim to sincerity. In a social situation these claims can be questioned and people may enter a negotiation about the claims (Dietz and Widdershoven, 1992). Besides communicative actions there are strategic actions, where people strive towards their own private goals, instead of being oriented towards mutual understanding. This is something which Searle's theory does not cover.

In general we can also see that the application of speech act based methods has special relevance concerning non-descriptive information, while it contributes less as regards descriptive information. It is applied to situations, where we typically find speech acts like 'request' and 'promise'.

In the original speech act theory, intentions played a crucial role. As a result, speech act theory is open for criticism as regards the relation between the private and the public (see above). However, even if this criticism can be directed towards speech act theory in the field of philosophy of language, we do not believe that it can be directly transferred to the IS-field. For the original speech act theory, it was truly essential to refer to intentions, in order to restrict what was counted as a speech act. It was noted that we can not count everything that people do with language as speech acts. If a person says 'Thank you!' this can be described as a set of different actions. We may say that he thanked the hearer, that he insulted the hearer (which could be an unintended effect in certain circumstances), that he moved a set of molecules in the air, he might even be said to have started a war in Guatemala (if we imagine an extraordinary causal chain from the utterance to the start of such a war). One way of restricting what is counted as a speech act is to limit the focus to what is intended by the speaker. He intended to thank the hearer. He did not intend to start a war in Guatemala. (But how do we know that?) 
How to understand the intentional part of speech act theory is an issue which we can not discuss in any depth here. However, we believe that when the speech act theory is used in the IS-field, intentions are not essential in the same way. (If they are referred to at all.) In this context, the theory is used in a design situation. Social agreements regarding the performance of future communicative actions are created. Whatever the intentions are during the performance of a promise, what is important to discuss and regulate are the succeeding actions. E.g., what will happen if a promise is not fulfilled? Winograd and Flores emphasize this and suggest that we should 'look at the social rather than the mental dimension' (Winograd and Flores, 1987, p. $60)$.

\subsection{The appeal to cognitive science in artificial intelligence and human-computer interaction}

Intentions and mental items are not only invoked in the design of IT-support for communicative actions (speech acts). Cognitive science is applied in a vast variety of fields in the IS-research area today. It is used to address a set of different problems, sometimes with a clear 'cognitivistic' or 'functionalistic' approach, where 'mental representations' are referred to in an unproblematic way. Whether the criticism of such theories in the area of philosophy of language can be transferred to our field is a question that needs considerable elaboration. Are there any practical deficiencies that can be related to this criticism? In this paper we have only limited space to comment on this issue. An important potential criticism is that the cognitive theories are limited to an individualistic perspective, where we in fact need to address social issues. This could be labeled as 'the individualistic fallacy'.

One large research area where cognitive science is applied is human-computer interaction, which at least traditionally has had a clear individualistic focus. However, we believe that it is reasonable to say that many practical research questions in this field are of such a character that a narrow focus on individual aspects is reasonable for practical reasons. These questions concern, e.g., the cognitive abilities of specific users or user groups to understand certain systems, to use them efficiently, to navigate and search information in complex hypertext systems, etc. Social and organizational factors can then be held constant.

Another area, where we believe that an individualistic focus and a lack of elaboration on social aspects have been more fatal, is the area of artificial intelligence in its early days (Winograd and Flores, 1986). In this field we find methods for knowledge 'acquisition' or knowledge 'elicitation', where the skills and competence of human experts are described in terms of mental representations. An extreme cognitivistic approach would be to view these studies as really revealing the mental representations and mental processing that constitute the skill or knowledge inside the experts. This in turn may justify a 'replacement approach' to systems development: Since the skill of an expert is assumed to be captured in a description of a mental representation, we can simply let a computer replace the expert in the future. In this way the knowledge of the expert will become more available to a larger group of people. However, such a perspective can be criticized from several perspectives. One such criticism can be formulated as follows: When replacing an expert with a computer program, there must be someone that is responsible for using the program in a certain situation, which in turn requires a good understanding of the program and a skill to understand the particular situation. Knowledge acquisition and systems design are always based on a set of assumptions about such skills and responsibilities in the organizational context. It is also reasonable to assume that a replacement of an expert by a computer based expert system will change these responsibilities and skills requirements for a set of people. Hence the organizational and social aspects can not be held constant in this context. 


\subsection{Usage holism in information systems development}

We would also like to mention representatives for a kind of usage holism in the field of information systems development. A method that is explicitly inspired by Wittgenstein is Ehn's Tools approach (Ehn, 1988). In this case the holistic aspect is dominating. Ehn emphasizes the need for the development team to be practically involved (as much as possible) in the language game of the users.

Susanne Bødker, although inspired by Ehn and the Tools approach, is not directly influenced by Wittgenstein (Bødker, 1991). Her Human-activity approach rather builds upon the theories of Leontjew. But her view could be described as sharing the holistic perspective: She does everything to directly approach the original usage environment. Bødker emphasizes practice and stresses that design means dealing with the involved user groups. The approach has its starting point in the users' original work environment, not with abstract diagrams or formal description techniques (such as task analysis). More concretely, she recommends simulation, exploratory programming, mock-ups, prototypes and other methods that emphasize practice and user participation in the design process.

We can see that the anti-theoretical language game approach within philosophy, has practical counterparts. There is a general problem of using abstract models in information systems development. An abstraction means that you focus on some aspects of a phenomenon and disregard others. In the context of information systems development it is often assumed that people can understand their particular needs in a future work situation just by making theoretical reflections and drawing abstract diagrams. It is a well-known fact that around $80 \%$ of development costs are spent during maintenance. Today there is a heavy focus on putting more effort and research on early requirements analysis. However, we may also need to develop good methods for design-use iteration, to avoid putting too much emphasis on abstract modeling.

Another type of problem related to the usage holism, concerns the general problem of rigid design of work and needed flexibility. Suchman criticizes Searle and others for focusing on social rules or background knowledge. Instead we should view the individual as a responsible actor. Each action is an improvisation, where social conventions constitute a resource (Suchman, 1986). In philosophy the basic problem is to passively understand language and communication. In information systems development the basic task is to actively design social interaction. The criteria for evaluating a theory within philosophy will therefore be different to the criteria in the area of information systems design. The choice of a certain theory or method in the area of information systems design may involve a desired structuring of a work situation, while the same theory will be viewed as too limited in scope from a philosophical point of view. Given that a certain theory is used as a basis in design, the question whether it is an appropriate theory has to do with the objectives of the organizational change: In what respect does one want to structure, control, and standardize the way people work and communicate? To what degree does one want to strive for effectiveness and control or for flexibility and empowerment of individual persons?

\subsection{Including the development activity}

It could be valuable to notice that our framework can be applied also to the development activity per se, since this activity often involves information as well. The referential aspects of the information used in the change activity often concern the work activity. This is illustrated in figure 4.

In this way we could discuss different perspectives on the development activity, in an analogous way. A development method could give an account of what specific documentation 
is needed, what specific models should be produced, and what they should be about (referential aspect). It could prescribe certain ways of working with the models, e.g., to achieve consensus among the stake holders (social aspects). Finally it could prescribe certain graphical presentation techniques to make the information easier to grasp for the individual developer (individual aspects). A theory about presentation techniques or about the social use of information can be applied both to the information used in the work activities and to the information used during development.

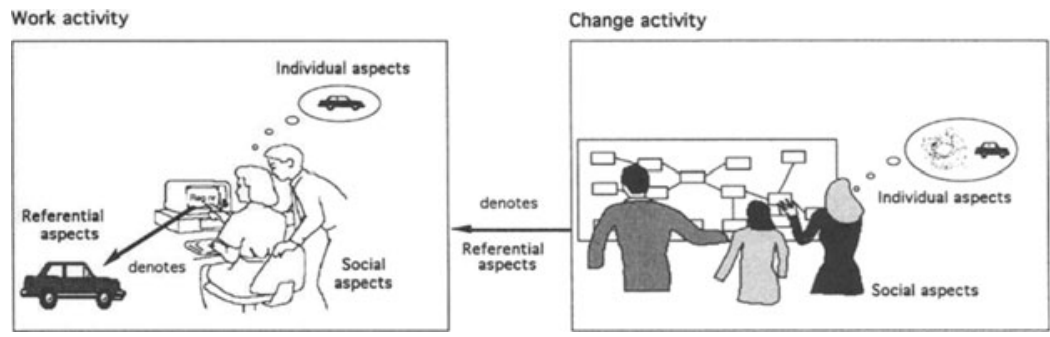

Figure 4 The framework applied to the development activity as well.

\subsection{Classification of different types of information system requirements}

If we include the development activity, our framework could be compared to 'the four worlds approach' (Jarke, 1993; Jarke et al, 1993; Jarke and Pohl, 1993), where the 'system world' corresponds to the system itself, the 'usage world' corresponds to the social and individual aspects, the 'subject world' corresponds to the referential aspects, and the 'development world' corresponds to the development activity.

The four worlds approach is suggested as a framework, e.g., to classify different nonfunctional requirements. The framework suggested in this paper could be used in a similar way. In a specific development project, we need to consider what the information in the future system is about. We have requirements on how the domain (the 'universe of discourse') is described. The information should be reliable. We have also requirements on how the information is presented to and handled by the individual user in an efficient way. Thirdly we have requirements on the system from a social point of view, e.g. as a communication media containing restrictions or template suggestions for future communication.

\subsection{The scope of the framework}

It may be of value to say something about what is not covered in the framework. Firstly, as mentioned above, we have not primarily focused on the change activity (even if we made a short digression in that direction). Secondly, our framework is information centred. This means that it does not have the capacity to illustrate different perspectives on work and work organizations. (The language game approach is in a way an exception, since it stresses the inseparability of communication and work.) Finally the basic analogy between the IS-field and the area of philosophy of language fails also when we consider the behavioral part of the system. Here we believe that the IS-field needs a considerable theory development in finding new metaphors for 'what people do with the computational power of computers'. 


\section{CONCLUDING REMARKS}

In this paper we have discussed analogies between theories of meaning and different perspectives on information systems. From an initial discussion about meaning we identify three areas in the language usage context, considered by many theories of meaning: the referential aspects, the individual aspects, and the social aspects. Different theories elaborate on these in different ways and to different degrees. In this paper we have shown that there are several analogies between theories and methods within the field of information systems development and theories of meaning in the field of philosophy of language, caused by more or less direct influences from different philosophical schools. There is a major mainstream focus on referential aspects. In recent years a shift of focus can be observed towards social usage aspects. Some parts of this new trend are historically related to corresponding theories within the area of philosophy of language. We have also discussed the risk that individualistic, cognitive theories are used to address social issues (the individualistic fallacy). Finally we have seen that the language game approach has been used to question the dominant role of abstract analysis and modeling in information systems development.

\section{ACKNOWLEDGEMENT}

The work with this article was partly sponsored by the Nature-project, Esprit Bra 6353, through Sisu - the Swedish Institute of Systems Development.

\section{LITERATURE}

Alston W P (1967) Meaning. The Encyclopedia of Philosophy, vol 5, MacMillan \& Free Press, Paul Edwards, Editor in Chief, (pp. 233-241)

Auramäki E, Lehtinen E, and Lyytinen K (1988) A speech-Act-Based Office Modeling Approach. ACM Transactions on Office Information Systems, 6(2), (pp. 126-152).

Auramäki E, Hirschheim R, and Lyytinen K (1992) Modelling Offices Through Discourse Analysis: The SAMPO Approach. The Computer Journal, 35, No 4 1992, (pp. 342-352)

Avramides A (1989) Meaning and Mind - An Examination of a Gricean Account of Language, Massachusetts Institute of Technology, The MIT Press.

Bickerton M J and Siddiqi J The Classification of Requirements Engineering Methods, In conference proceedings: IEEE Symposium on Requirements Engineering, RE'92, 1992

Bødker S (1991) Through the Interface - A Human Activity Approach to User Interface Design, Lawrence Erlbaum Associates, Inc.

Dietz J L G and Widdershoven G A M (1992) A comparision of the linguistic theories of Searle and Habermas as a basis for communication supporting systems. Linguistic Instruments in Knowledge Engineering Amsterdam, North-Holland.

Ehn P (1988) Work-Oriented Design of Computer Artifacts, Falköping, Gumessons

Flores F, Graves M, Hartfield B, and Winograd T (1988) Computer Systems and the Design of Organizational Interaction. ACM Transactions on Office Information Systems, 6 (2), (pp. 87-108)

Føllesdal D, Walløe L, and Elster J (1990) Argumentasjonsteori, språk og vitenskapsfilosofi, 1977, Oslo, Universitetsforlaget AS

Hirscheim R and Klein H K (1989) Four Paradigms of Information Systems Development. Communications of the ACM, volume 32 (pp. 1199-1216)

Jarke M (Ed.) Database Application Engineering with DAIDA, 1993, Springer Verlag 
Jarke M, Bubenko J A jr, Rolland C, Sutcliffe A, and Vassiliou Y (1993) Theories Underlying Requirements Engineering: An Overview of NATURE at Genesis In: conference proceedings: IEEE Symposium on Requirements Engineering, RE'93, San Diego, CA, Jan.

Jarke $\mathrm{M}$ and Pohl $\mathrm{K}$ Establishing Visions in Context: Towards a Model of Requirements Processes, 93-08, 1993, Informatik V, Ahornstr. 55, 5100 Achen, Germany.

Lyons J (1981) Language, Meaning \& Context, 1986, Fontana Paperbacks.

Lyytinen K (1985) Implications of Theories of Langugage for Information Systems. MIS Quarterly March 1985, (pp. 61 - 73)

Martin R (1993) The Meaning of Language Cambridge, the MIT Press

Medina-Mora R, Winograd T, Flores R, and Flores F (1993) The Action Workflow Approach to Workflow Management Technology In conference proceedings: Third European Conference on Computer Supported Cooperative Work, (pp. 281-288), Milano, Italy

Pagin P (1994) Moderna meningsteorier. Filosofisk Tidskrift, 1/94, pp.3-25, Bokförlaget Thales

Schäl T and Zeller B (1993) Supporting Cooperative Processes with Workflow Management Technology Tutorial preceding: Third European Conference on Computer Supported Cooperative Work, Milano, Italy, 1993.

Searle J R (1969)Speech Acts. An Essay in the Philosophy of Language, 1969, Cambridge University. Press.

Searle J R (1979) Expression and Meaning, Cambridge, 1979, Cambridge University Press

Searle J R and Vanderveken D (1985) Foundations of Illocutionary Logic, Cambridge, 1985, Cambridge University Press.

Schmidt K (1993), Modes and mechanisms of interaction in cooperative work. Computational Mechanisms of Interaction for CSCW - COMIC Deliverable 3.1. Lancaster, Lancaster University.

Suchman L (1993), Do Categories Have politics? The language action perspective reconsidered In proceedings of ECSCW' 93.

Winograd T (1987-88) A Language/Action Perspective on the Design of Cooperative Work. Human-Computer Interaction, 3-5, (pp. 3-30) 1987-88

Winograd T and Flores F (1986) Understanding Computers and Cognition, Massachusetts, 1986, Addison-Wesley Publishing Company Inc.

Wittgenstein L (1958) Philosophical Investigations, 1978, Basil Blackwell \& Mott, Ltd., Oxford

\section{BIOGRAPHY}

Peter Holm is a PhD student at the Department of Computer and Systems Science, Stockholm University. He received a Fil. Lic. in 1993. Currently he has a research grant at this departmnet to finish his thesis. From 1992 to 1994 he was employed by the Swedish Institute for Systems Development (SISU).

Klas Karlgren holds a degree in psychology and philosophy and a degree in information processing and computer sciences, both from Stockholm University. From 1993 to 1994 he was employed at SISU where he studied cognitive aspects of human-computer interaction. He is currently a PhD student at the Department of Computer and Systems Science at Stockholm University where he is involved in a research project on conceptual shifts in learning, and user modeling. 